\title{
Scandium: An efficient dopant to modulate the optical spectrum of vanadium dioxide $\left(\mathrm{VO}_{2}\right)$
}

\author{
Devanshi Bhardwaj $^{1}$ D $\cdot$ A. M. Umarji ${ }^{1}$
}

Received: 30 March 2020 / Accepted: 12 August 2020 / Published online: 25 August 2020

(c) Springer Nature Switzerland AG 2020

\begin{abstract}
Transparency of $\mathrm{VO}_{2}$ thin films in the visible region is an important aspect of study for its use in smart window applications. In this regard, we experimentally validate the theoretical prediction regarding the influence of scandium (Sc) doping on modulating the optical spectrum of $\mathrm{VO}_{2}$. Sc-doped nano-crystalline $\mathrm{VO}_{2}$, bulk and thin films were synthesised using a two-step process involving a rapid non-equilibrium solution combustion process and ultrasonic nebulised spray pyrolysis of aqueous combustion mixture respectively; followed by a reduction step. The presence of Sc was determined by $\mathrm{X}$-ray photoelectron spectroscopy where a peak observed at $530.06 \mathrm{eV}$ is attributed to Sc-O interaction. Raman spectra showed a shift in $611 \mathrm{~cm}^{-1}$ peak position to a lower wavenumber due to tensile strain arising from Sc doping. Sc-doped $\mathrm{VO}_{2}$ thin films showed semiconductor to metal transition of four orders of magnitude change in resistance. Sc-doping increased the band gap from $1.76 \mathrm{eV}$ for undoped to $2.02 \mathrm{eV}$ with $2.0 \mathrm{at}$. \% of doping thereby making the films more transparent in the visible region of the optical spectrum. This shift in the band gap of $\mathrm{VO}_{2}$ was consistent with the theoretical reports. Thus, $\mathrm{Sc}$ is a potential dopant for modulating the optical spectrum of $\mathrm{VO}_{2}$ for its application in smart windows.
\end{abstract}

Keywords Vanadium dioxide $\cdot$ Doping $\cdot$ Smart windows $\cdot$ Optical spectrum $\cdot$ Scandium

\section{Introduction}

Vanadium dioxide $\left(\mathrm{VO}_{2}\right)$ is a transition metal oxide which finds use in various applications like thermochromic devices [1], micro-bolometer [2], IR-photodetector [3], metamaterial $[4,5]$, smart windows [6, 7], thermal switching [8], batteries [9, 10], memristic devices [11], THz modulation devices [12] etc. It is been extensively studied due to its ability to undergo a first order phase transition accompanied by semiconductor-to-metal transition (SMT) at 68 ${ }^{\circ} \mathrm{C}\left(\mathrm{T}_{S M T}\right)$. During the phase transition, a change in crystal structure from monoclinic (M1) phase $\left(P 2_{1} / c\right)$ to tetragonal (R) phase $\left(\mathrm{PL}_{2} / \mathrm{mnm}\right)$ is observed which leads to change in the V-V bond length [13]. During the SMT transition, $\mathrm{VO}_{2}$ shows a change in electrical resistivity, high resistance
$\left(T<T_{S M T}\right)$ to low resistance $\left(T>T_{S M T}\right)$ as well as in the optical response with a slight hysteresis which is attributed to the stress involved due to structural change and the change in latent heat [14]. $\mathrm{VO}_{2}$ acts as IR transparent at $\mathrm{T}<\mathrm{T}_{S M T}$ and acts as IR reflector at $\mathrm{T}>\mathrm{T}_{S M T}$ [15]. Due to this property, it is been for used as a coating material on windows called as smart windows $[6,16]$. Various methods like sol-gel [17], pulsed laser deposition [18-20], chemical vapour deposition [21], sputtering [22, 23] etc. have been employed for fabrication of doped as well as undoped $\mathrm{VO}_{2}$ thin films.

There are few limitations to use $\mathrm{VO}_{2}$ for smart window applications: (a) High $\mathrm{T}_{S M T}$, which has been overcome by adding dopants in vanadium site $[17,24-30]$ and the minimum value for $\mathrm{T}_{S M T}$ has been observed to be $\sim 25$

Electronic supplementary material The online version of this article (https://doi.org/10.1007/s42452-020-03332-7) contains supplementary material, which is available to authorized users.

Devanshi Bhardwaj, devanshib@iisc.ac.in | ${ }^{1}$ Materials Research Centre, Indian Institute of Science, Bengaluru 560012, India. 
${ }^{\circ} \mathrm{C}$, when $\mathrm{W}$ is doped into the system. Many reasons have been reported where the choice of dopant depends on its effect on the crystal structure. This influence of dopant on the crystal structure decides the reduction of transition temperature $\left(T_{S M T}\right)$. It is reported in the literature that, when the structure of doped $\mathrm{VO}_{2}$ is close to that of tetragonal phase, a reduction in $\mathrm{T}_{S M T}$ will be observed. This is attributed to reduction in $\beta$-angle [31]. (b) The reduced transmission in visible range after coating $\mathrm{VO}_{2}$ on the glass resists its use as a smart window material [27, 32]. The dopants added either reduce the $\mathrm{T}_{S M T}$ or manipulate the optical spectrum. When $\mathrm{W}, \mathrm{Mo}$ is doped into $\mathrm{VO}_{2}$, $\mathrm{T}_{S M T}$ decreases $\left(\sim 25^{\circ} \mathrm{C}\right)$ but the optical band gap is very low thereby making the film to be dark in colour. When dopants like Mg, F [27, 33, 34] etc., are doped the band gap increases making the film transmit more light, but these dopants do not induce any change in $\mathrm{T}_{S M T}$. In order to come up with a better solution, co-doped system have been introduced [28] which enhances the visible transmittance but not up to the extent that it can be commercially used. To use $\mathrm{VO}_{2}$ as an efficient smart window material, both the problems need to be overcome at the same time.

Sun et al. [35], depending upon the results obtained from DFT calculations suggests that of all the different transition metal that can be used for doping, scandium $(\mathrm{Sc})$ is the best dopant. Doping $\mathrm{Sc}$ into $\mathrm{VO}_{2}$ reduces the $\beta$ -angle so that the structure is closer to tetragonal phase of $\mathrm{VO}_{2}$ thereby reducing the $T_{S M T}$ as well as it enhances the optical spectrum as the interaction between $\mathrm{Sc}^{3+}$ and $\mathrm{O}^{2-}$ is weaker than $\mathrm{V}^{4+}$ and $\mathrm{O}^{2-}$, thereby will induce a blue shift in the absorption spectrum [35].

Herein, we validate these theoretical prediction experimentally. We have synthesised bulk of scandium doped $\mathrm{V}_{2} \mathrm{O}_{5}$ using rapid solution combustion synthesis (SCS) followed by a reduction step to get scandium doped $\mathrm{VO}_{2}$. Thin films were deposited using simple, cost-effective method i.e., Ultrasonic Nebulised Spray Pyrolysis of Aqueous Combustion Mixture (UNSPACM), first to get phase pure $\mathrm{Sc}$-doped $\mathrm{V}_{2} \mathrm{O}_{5}$ thin films on quartz substrate, followed by reduction step to get $\mathrm{VO}_{2}$. Bulk and thin film samples were further characterized to determine the effect of Sc doping on $\mathrm{T}_{S M T}$ and optical spectrum.

\section{Experimental section}

\subsection{Synthesis of bulk materials}

For synthesis of bulk material, solution combustion synthesis method was employed. Aqueous combustion mixture ( $\mathrm{ACM}$ ) was prepared using ammonium metavanadate $\left(\mathrm{NH}_{4} \mathrm{VO}_{3}\right)$, scandium nitrate $\left(\mathrm{Sc}\left(\mathrm{NO}_{3}\right)_{3}\right)$ as metal source (Oxidizer, $\mathrm{O})$ and urea $\left(\mathrm{CH}_{4} \mathrm{~N}_{2} \mathrm{O}\right)$ as the fuel $(\mathrm{F})$. Stoichiometric amounts of the precursors were dissolved in dilute nitric acid and water calculated using Eq. 1 so that the oxidiser to fuel ratio is equal to 1 [36],

$$
\begin{aligned}
& 5 \mathrm{CH}_{4} \mathrm{~N}_{2} \mathrm{O}+2(1-x) \mathrm{NH}_{4} \mathrm{VO}_{3}+2 x \mathrm{Sc}\left(\mathrm{NO}_{3}\right)_{3} \\
& \quad \rightarrow\left(V_{1-x} \mathrm{Sc}_{x}\right)_{2} \mathrm{O}_{5}+\mathrm{H}_{2} \mathrm{O}+\mathrm{NO}_{2}
\end{aligned}
$$

where $\mathrm{x}$ is the amount of scandium doped into the system as mentioned in Table 1. The schematics is shown in Fig. 1.

ACM was kept in a furnace pre-heated at $500^{\circ} \mathrm{C}$. The yellow bulk Sc-doped $\mathrm{V}_{2} \mathrm{O}_{5}$ obtained from self-propagating combustion reaction was ground and subjected to reduction treatment in $\mathrm{N}_{2}$ atmosphere saturated with hydrocarbon at $550^{\circ} \mathrm{C}$ for $30 \mathrm{~min}$ [37]. In order to compare the optical results with $\mathrm{W}$ - and Mo-doped $\mathrm{VO}_{2}$, the bulk samples for 2.0 at. \% W doped and 1.8 at. \% Mo doped were also synthesised. 2.0 at. \% W doping and 1.8 at. \% Mo doping was considered as these are the highest dopant levels for W- and Mo-doping respectively, that leads to reduction in $\mathrm{T}_{S M T}[24,38]$.
Table 1 Sample code for doped as well as undoped

\begin{tabular}{|c|c|c|c|c|c|c|}
\hline \multirow[t]{3}{*}{ Doping at. \% } & \multirow{3}{*}{$\begin{array}{l}\text { Composition } \\
\mathrm{x}\end{array}$} & \multirow[t]{3}{*}{ Elements } & \multicolumn{4}{|c|}{ Sample code } \\
\hline & & & \multicolumn{2}{|l|}{ Bulk } & \multicolumn{2}{|c|}{ Thin film } \\
\hline & & & $\mathrm{V}_{2} \mathrm{O}_{5}$ & $\mathrm{VO}_{2}$ & $\mathrm{~V}_{2} \mathrm{O}_{5}$ & $\mathrm{VO}_{2}$ \\
\hline 0 & 0 & - & BV & RBV & TV & RTV \\
\hline 0.5 & 0.005 & Sc & BVS0.5 & RBVS0.5 & & \\
\hline 1.0 & 0.01 & Sc & BVS1.0 & RBVS1.0 & TVS1.0 & RTVS1.0 \\
\hline 1.5 & 0.015 & Sc & BVS1.5 & RBVS1.5 & & \\
\hline 2.0 & 0.02 & Sc & BVS2.0 & RBVS2.0 & TVS2.0 & RTVS2.0 \\
\hline 6.25 & 0.0625 & Sc & BVS6.25 & RBVS6.25 & & \\
\hline 2.0 & 0.02 & W & BVW2.0 & RBVW2.0 & & \\
\hline 1.8 & 0.018 & Mo & BVM1.8 & RBVM1.8 & & \\
\hline
\end{tabular}
samples 
Fig. 1 a Schematics for solution combustion synthesis, $\mathbf{b}$ UNSPAM setup (a)

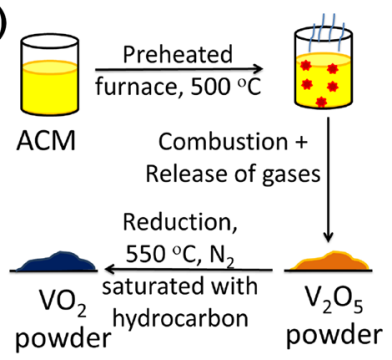

$\mathrm{ACM}: \mathrm{M}\left(\mathrm{NO}_{3}\right)_{3}+$ Urea

$\mathrm{M}$ : Metal (V and Sc) (b)

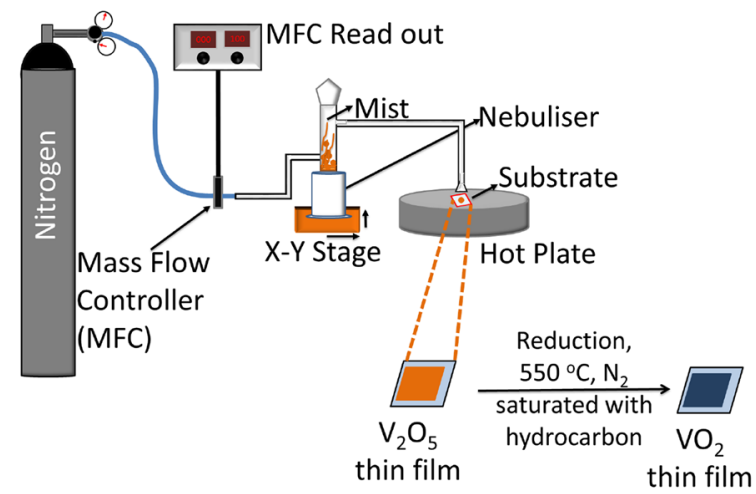

\subsection{Synthesis of thin films}

Scandium doped vanadium dioxide thin films was synthesised via. UNSPACM using a home built setup [39], schematics for which is shown in Fig. 1. Sc-doped $\mathrm{V}_{2} \mathrm{O}_{5}$ was synthesized on a quartz substrate. The ultrasonically nebulised mist, containing the redox mixture, was carried to the hot substrate by $\mathrm{N}_{2}$ gas flowing at $1000 \mathrm{sccm}$. The micrometer sized droplets instantaneously pyrolysed on encountering with the quartz substrate. The substrate maintained at $600{ }^{\circ} \mathrm{C}$. The films were synthesised at high temperature to get a crystalline phase of $\mathrm{V}_{2} \mathrm{O}_{5}$. The films were deposited for $10 \mathrm{~min}$. The films thus obtained were reduced by treating the product in $\mathrm{N}_{2}$ atmosphere saturated with hydrocarbon [40] at $550^{\circ} \mathrm{C}$ for $2.5 \mathrm{~h}$. The sample codes are listed in Table 1.

\subsection{Characterization}

Phase confirmation was done on both bulk and thin film samples by XRD using PANALYTICAL with $\mathrm{Cu}-\mathrm{K} \alpha$ as the $\mathrm{X}$-ray radiation $(\lambda=1.5418 \AA$ ). Raman measurements were done to confirm the phase formation using Horiba JobinYvon HR-Raman-123microPL spectrometer with a green laser having a wavelength of $523 \mathrm{~nm}$. The surface morphology was determined using a F50 Inspect Field Emission SEM and Carl-Ziess scanning electron microscope, accelerating voltage of $25 \mathrm{kV}$. Transmission electron microscope, JEOL 2100F (TEM) was used at an accelerating voltage of $200 \mathrm{kV}$ to determine the morphology of bulk samples. To determine SMT for bulk samples, DSC measurements were carried out in METTLER-TOLEDO DSC1 system. For thin films, electrical measurements were carried out on a DC probe station equipped with an ATT thermal controller coupled with a B1500A semiconductor device analyser. UV Visible measurements were done using Perkin-Elmer spectrophotometer (Lambda 750) for determination of band gap. FTIR measurements were done as a function of temperature for the thin films using Agilent Carry 600 Fourier Transform infrared spectrometer in reflectance mode. XPS measurements were done using Axis Ultra DLD from Kratos to study the influence of doping on the structural environment using Al-K $\alpha \mathrm{X}$-ray source. The peak fitting was done using Fityk software.

\section{Results and discussions}

\subsection{Bulk samples}

\subsubsection{Structural characterization}

Doping $\mathrm{VO}_{2}$ is a better way to reduce the $\mathrm{T}_{S M T}$ and is mostly due to the alteration in the crystal structure. DFT calculations suggests that whenever the crystal structure is near to tetragonal phase, a reduction in transition temperature is observed [35].

In order to determine the crystal structure, X-Ray diffraction studies were done. As seen in Fig. 2a, the peaks perfectly match with JCPDS file no: 01-077-2498 for $\mathrm{V}_{2} \mathrm{O}_{5}$, showing an orthorhombic crystal system with space group, Pmmn. The peaks match with JCPDS file no: 00-191398 for $\mathrm{VO}_{2}$ (Fig. 2b) showing a monoclinic crystal system with space group $P 2_{1} / c$. The BV sample is crystalline in nature. The crystalline nature reduces with increasing doping concentration of scandium in $\mathrm{VO}_{2}$ bulk sample (Fig. 2b). During synthesis of $\mathrm{V}_{2} \mathrm{O}_{5}$ by SCS, though the ignition temperature is maintained at $500^{\circ} \mathrm{C}$, it is reported that at the microscopic scale the temperature can be as high as $1500^{\circ} \mathrm{C}$. This is achieved at an optimum equivalence ratio of fuel $(F$, urea) and oxidizer $(O$, metal nitrate) (defined as oxidizer to fuel ratio; O/F) of unity [41, 42]. Due to this effect, the crystallites are well formed, leading to sharp peaks in the XRD pattern. However, the reduction step to get phase pure $\mathrm{VO}_{2}$, is carried out at $550^{\circ} \mathrm{C}$. This temperature is probably too low to develop well defined crystallites, thereby resulting in broader, or low crystallinity as seen from XRD pattern. 
Fig. 2 XRD pattern of doped as well as undoped $\mathbf{a} \mathrm{V}_{2} \mathrm{O}_{5}$ and $\mathbf{b}$ $\mathrm{VO}_{2}$ bulk samples

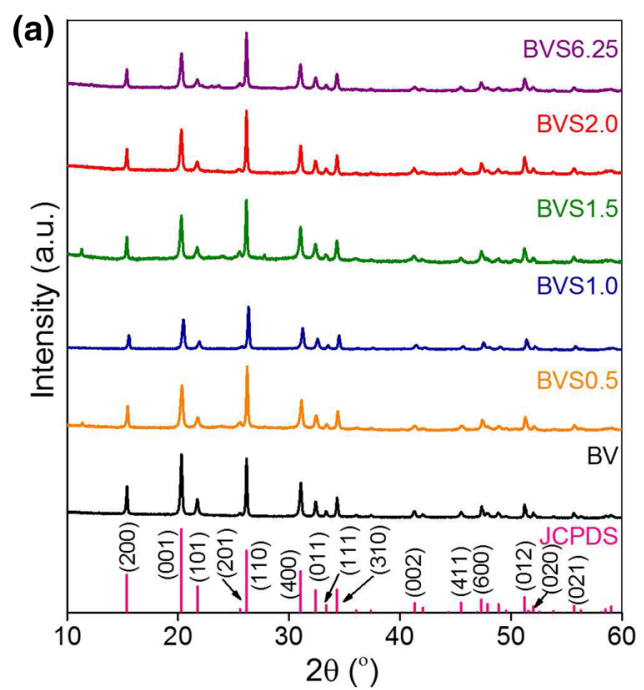

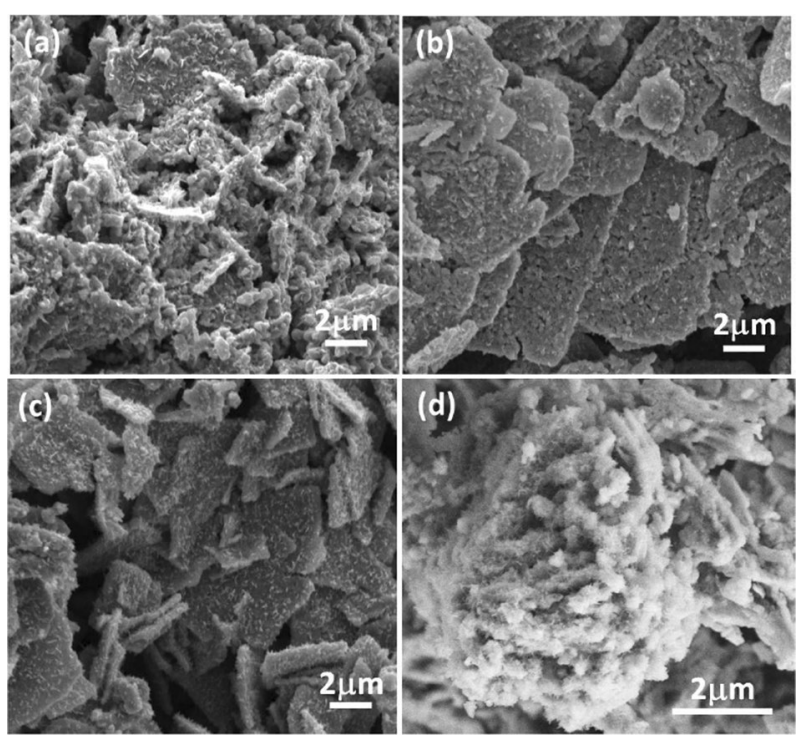

Fig. 3 SEM images of a RBV, b RBVS1.0, c RBVS2.0 and d RBVS6.25 samples

\subsubsection{Morphology: SEM}

Figure S1 (supplementary information) show the SEM images of the doped and undoped $\mathrm{VO}_{2}$ formed before reduction process. The powder samples shows porous morphology which is due to the release of gases as explained from Eq. 1. Figure 3 shows the SEM images of the doped and undoped $\mathrm{VO}_{2}$ formed after reduction process. The surface morphology shows presence of agglomerated sheets (Fig. $3 a-c)$, which are porous. Figure $3 d$ shows the presence of porous agglomerated particles for RBVS6.25 sample.

For all the samples a small needle like projection was seen coming out of the surface. TEM of RBVS2.0 shows sheet morphology as seen in Fig. 4a. The polycrystalline nature of the sample is confirmed by the electron diffraction pattern (Fig. 4a). The presence of scandium is confirmed by the EDS data (Fig. 4b).
Fig. 4 a TEM image for RBVS2.0; b EDS data for RBVS2.0

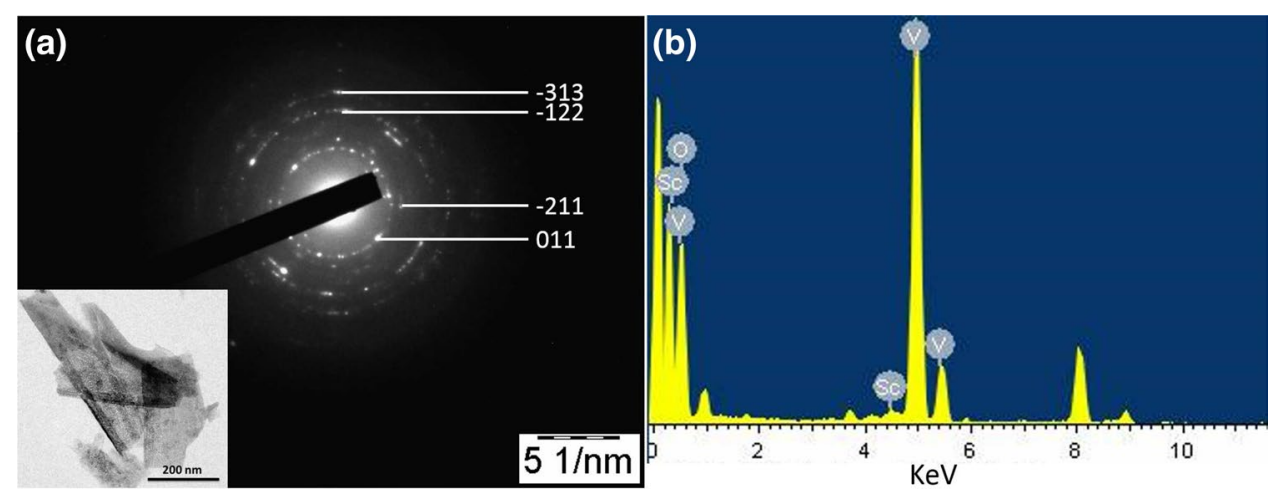




\subsubsection{DSC on bulk samples}

Phase transition for bulk samples was determined by DSC. The measurement was carried out for both heating and cooling from -80 to $130^{\circ} \mathrm{C}$ for these samples. DSC curves are shown in Fig. 5 . The data is shown only for 10 to $100^{\circ} \mathrm{C} . \mathrm{VO}_{2}$ sample showed a transition at 68 ${ }^{\circ} \mathrm{C}$ with a heating onset at $60^{\circ} \mathrm{C}$ whereas a for cooling the onset was around $62^{\circ} \mathrm{C}$ and the peak was observed at $60^{\circ} \mathrm{C}$ thereby leading to a hysteresis. As the dopant concentration was increased into the system, broader transition was observed which is probably due to the lower crystallinity as seen from Fig. 2b. For better understanding of the $T_{S M T}$, electrical measurement of thin films was considered. This is discussed in Sect. 3.2.4.

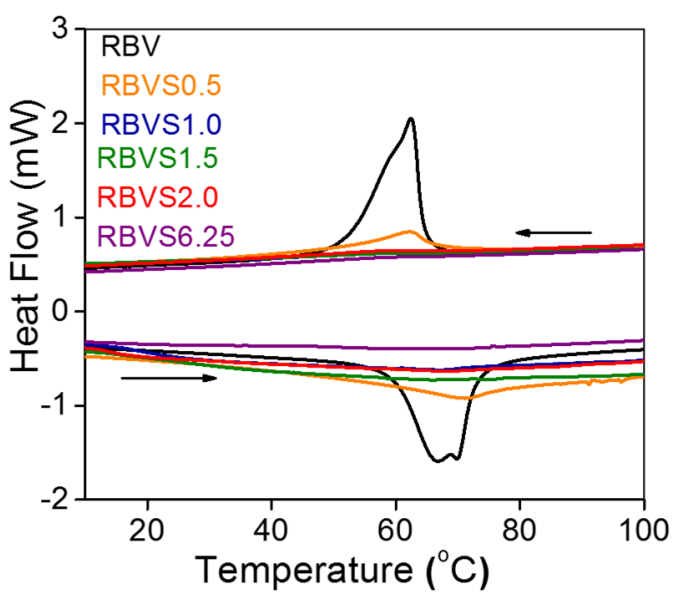

\subsubsection{Optical measurements: band gap determination}

Scandium doping into $\mathrm{VO}_{2}$ was supposed to induce a blue-shift in the absorption spectrum [35] as suggested by the DFT calculation. To validate that UV measurement was done on the powder samples by diffuse reflectance spectroscopy (DRS). Using Tauc's plot i.e., $(\alpha h v)^{n}$ vs $h v$ plot (Fig. 6a) where $\alpha=2.303 \log$ (Absorbance (A)), band gap was determined for the powder samples. $n$ was considered to be 2 as $\mathrm{VO}_{2}$ is a direct band gap semiconductor.

Sc-doping gives a blue shift in the spectrum thereby making it more transparent the reason being that $\mathrm{Sc}^{3+}$ posses no d-electrons. Because of that, $\mathrm{Sc}^{3+}-\mathrm{O}^{2-}$ electrostatic attraction is weaker than $\mathrm{W}^{6+}-\mathrm{O}^{2-}, \mathrm{Mo}^{6+}-\mathrm{O}^{2-}$ and $\mathrm{V}^{4+}-\mathrm{O}^{2-}$ thereby increasing the band gap and hence inducing a blue shift [35]. Figure $6 \mathrm{~b}$ shows that the band gap value increases for scandium doping till 2.0 at. \% thus showing a blue shift in the absorption edge, but the band gap decreases when dopant concentration is varied from 2 to 6.25 at. \% (theoretical value) thereby showing that the properties are deteriorating when scandium doping concentration increases further.

We can see that as compared to W and Mo, the Scdoped $\mathrm{VO}_{2}$ shows higher band gap values thereby validating the reason (Fig. 6b). Thus, it can be inferred that 2.0 at. \% of scandium in vanadium dioxide system is the best dopant concentration to get maximum blue shift.

\subsection{Thin film samples}

For smart windows applications thin film of $\mathrm{VO}_{2}$ are usually used. As seen from the UV data for bulk samples (Fig. 6), the optical band gap for bulk samples reduced as the concentration of scandium increased from 2.0 to 6.25 at. \%. Thus, for the thin films, synthesis (explained

Fig. 5 DSC of bulk samples

Fig. 6 a Tauc's plot for determining band gap. $\mathbf{b}$ Comparison of band gap of Sc-doping in $\mathrm{VO}_{2}$ with $\mathrm{W}$ - and Mo-doping (a)

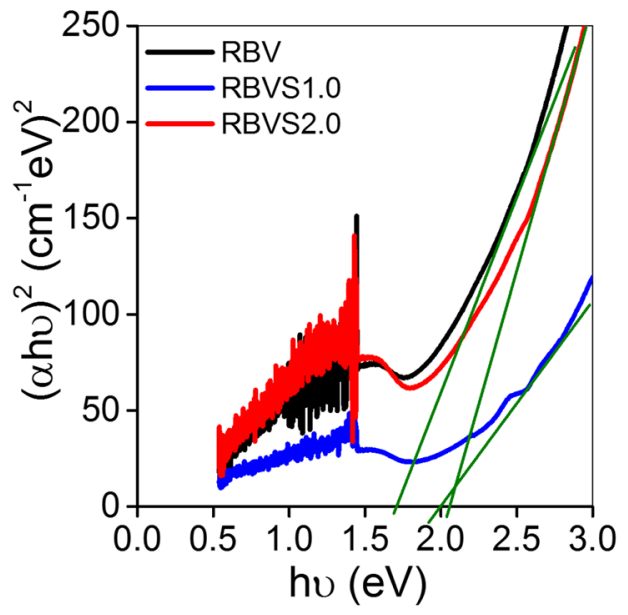

(b)

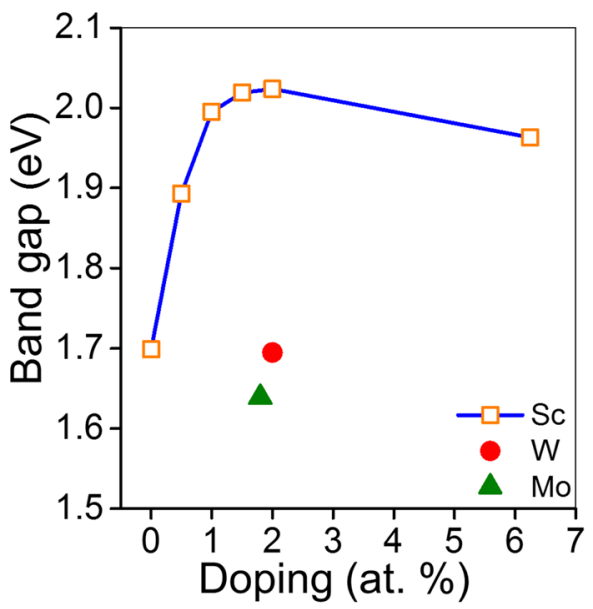


in "Experimental section") and measurements were limited to 2.0 at. \% dopant concentration.

\subsubsection{Structural characterization: XRD}

The XRD data for $\mathrm{V}_{2} \mathrm{O}_{5}$ thin film perfectly match with JCPDS file no: 01-077-2498 (Fig. 7a) showing an orthorhombic crystal system with space group Pmmn and peaks match with JCPDS file no: 00-19-1398 for $\mathrm{VO}_{2}$ (Fig. 7b) showing a monoclinic crystal system with space group $P 2_{1} / c$ as seen for the powder sample. The $\mathrm{V}_{2} \mathrm{O}_{5}$ thin film on the quartz substrate seem to show an orientation about (00l) direction as can be seen from XRD (Fig. 7a). After reduction no such orientation is observed in XRD thereby giving us a polycrystalline $\mathrm{VO}_{2}$ film (Fig. 7b). The broad peak at $2 \theta=21.525^{\circ}$ is due to quartz substrate for thin films (Fig. 7a, b).

\subsubsection{Morphology: SEM}

Figure 8 shows the SEM of undoped (RTV) as well as Scdoped thin film (RTVS1.0 and RTVS2.0) obtained after reduction. The films are highly porous in nature due to the release of gases during the pyrolysis process as explained by Eq. 1. A slight change in the morphology was observed with increasing $\mathrm{Sc}$ doping in $\mathrm{VO}_{2}$ thin films.

\subsubsection{Raman and XPS measurements}

The Raman peaks for thin film (Fig. 9) exactly match with the values reported in the literature as shown in Table S1 (supplementary information). In Raman spectra the lower wavenumber bands $\left(<400 \mathrm{~cm}^{-1}\right)$ are allocated to $\mathrm{V}-\mathrm{O}-\mathrm{V}$ bending modes; intermediate wavenumber bands $\left(400-800 \mathrm{~cm}^{-1}\right)$ are observed due to $\mathrm{V}-\mathrm{O}-\mathrm{V}$ stretching modes; and higher wavenumber bands $\left(>800 \mathrm{~cm}^{-1}\right)$, are assigned to $\mathrm{V}=\mathrm{O}$ stretching modes of distorted octahedra and distorted square-pyramids. The phonon modes in
Fig. 7 XRD pattern of doped as well as undoped $\mathbf{a} \mathrm{V}_{2} \mathrm{O}_{5}$ and $\mathbf{b}$ $\mathrm{VO}_{2}$ of thin films
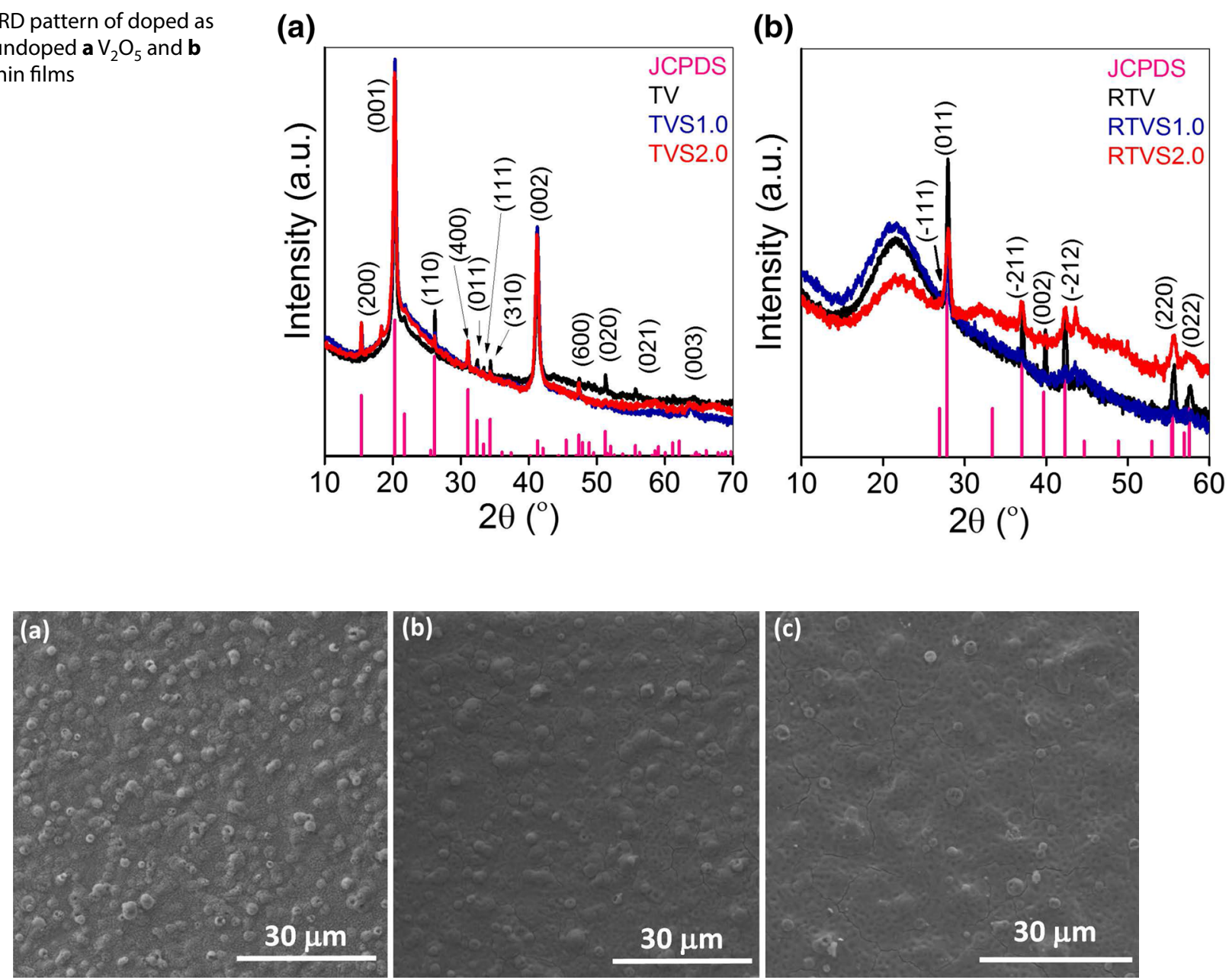

Fig. 8 SEM images of a RTV; $\mathbf{b}$ RTVS1.0 and c RTVS2.0 thin film 
$\mathrm{VO}_{2}(\mathrm{M} 1)$ are are very complex and are mostly due to the stretching and bending of $\mathrm{V}-\mathrm{O}-\mathrm{V}$ bonds and zigzag chains of $\mathrm{V}-\mathrm{V}$ [44].The shift in $611 \mathrm{~cm}^{-1}$ peak towards lower wavenumber as seen in Table 2 , is observed with doping and is attributed to the alteration in the $\mathrm{V}-\mathrm{O}-\mathrm{V}$ bonds upon doping. To the authors best understanding upon doping $\mathrm{Sc}$ into the system there are formation of Sc-O-V bonds which lead to tensile strain into the system thereby shifting the peak to a lower wavenumber.

XPS measurements were done on the undoped and Sc-doped thin film using Al-K $\alpha$ as the source. The peak position is referenced using C1s (B.E. $=284.8 \mathrm{eV}$ ) spectra as reference. $01 \mathrm{~s}$ and $\mathrm{V} 2 \mathrm{p}$ spectra usually fall in the same binding energy (B.E.) region. On deconvoluting the XPS spectra we can find out the oxidation states present in RTV and RTVS2.0. Figure S2 of supporting information shows the deconvoluted $\mathrm{V} 2 \mathrm{p}$ and $\mathrm{O} 1 \mathrm{~s}$ spectra. The peak position, FWHM and area ratio of corresponding oxidation states are tabulated in Table 3. $V 2 p_{3 / 2}$ peak was deconvoluted into three peaks corresponding to $\mathrm{V}^{+5}, \mathrm{~V}^{+4}$ and $\mathrm{V}^{+3}$ oxidation states after Gaussian background subtraction using Fityk software. From the area ratio for various oxidation state it was observed that upon adding scandium the amount of $\mathrm{V}^{+5}$ and $\mathrm{V}^{+3}$ oxidation state increased (Table 3 ) thereby suggesting that $\mathrm{Sc}-\mathrm{O}$ interactions are taking place. This interaction is in good agreement with the Raman data where the shift in wavenumber was attributed to the strain

Table 2 Wavenumber corresponding to $\mathrm{A}_{1 g}$ mode for $\mathrm{VO}_{2}$ thin film

\begin{tabular}{lllll}
\hline Modes & \multicolumn{4}{l}{ Wavenumbers $\left(\mathrm{cm}^{-1}\right)$} \\
\cline { 2 - 5 } & Ref [43] & RTV & RTVS1.0 & RTVS2.0 \\
\hline $\mathrm{A}_{1 \mathrm{~g}}$ & 616 & 611 & 609 & 606 \\
\hline
\end{tabular}

induced due to Sc-O-V bonds formation. This interaction can also be confirmed by 01s spectra [Figure S2 (supplementary information); RTVS2.0] where a peak at $530.06 \mathrm{eV}$ is attributed to Sc-O interaction [45].

\subsubsection{Electrical characterization}

Figure 10a shows resistance for Sc-doped system as a function of temperature for both heating and cooling experiments done on the thin film synthesised using UNSAPCM. The electrical property was determined by an in-plane measurement using a two-probe DC probe station. The transition temperature for undoped (RTV) thin film was observed at $82^{\circ} \mathrm{C}$. This increase in the transition temperature is due to presence of quartz substrate. The thin film showed a four orders of resistance change. The sample did not show any change in the transition temperature rather the thermal hysteresis increased upon scandium doping (2.0 at. \%) as can be seen from Fig. $10 \mathrm{~b}$.

To further understand the trend, activation energy was calculated for the heating curves of undoped and doped thin films using the Arrhenius equation:

$R=R_{o} e^{E_{a} / K_{B} T}$

The slope of the plot between $\ln R(T)$ versus $1 / K_{B} T$ was calculated to determine the activation energy for both semiconducting and metallic phase of Sc-doped $\mathrm{VO}_{2}$ (Fig. 10c). Figure $10 \mathrm{~d}$ shows the change in activation energy for both semiconducting and metallic phase of Scdoped $\mathrm{VO}_{2}$ as a function of scandium doping. We observe that the activation energy remains constant till 1.0 at. \% doping and then decreases as the concentration is further increased to 2.0 at. \% in the semiconducting phase.
Fig. 9 Raman spectra of doped as well as undoped $\mathbf{a} \mathrm{V}_{2} \mathrm{O}_{5}$ and b $\mathrm{VO}_{2}$ thin films (a)

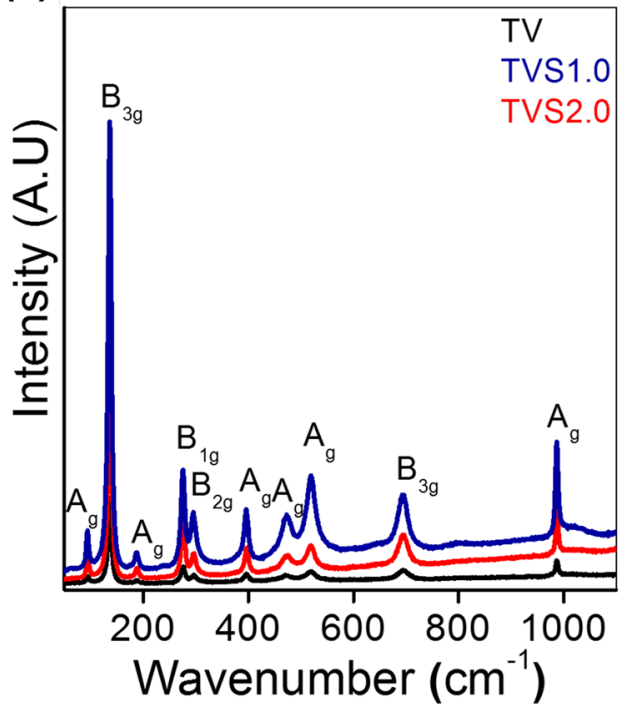

(b)

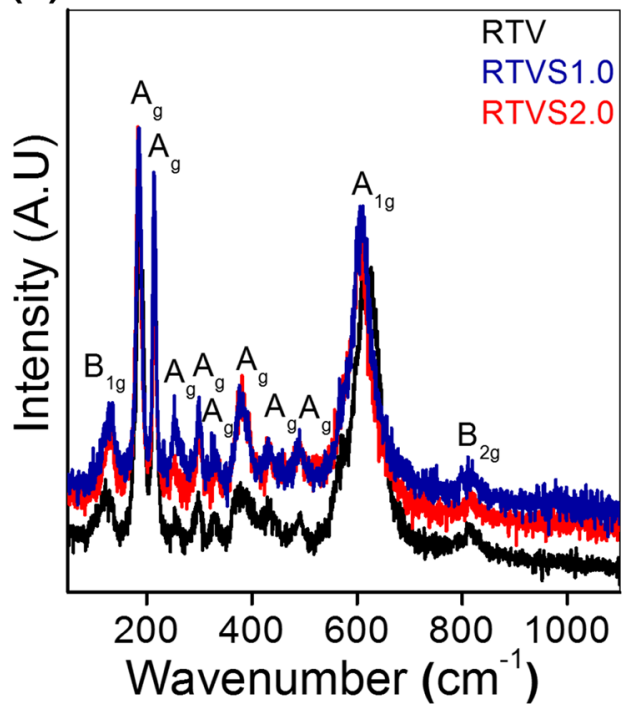


Table 3 Oxidation states along with the peak position, FWHM values and area ratio determined after deconvoluting XPS data
Fig. 10 a Resistance versus temperature, $\mathbf{b}$ derivative plot for Sc-doped $\mathrm{VO}_{2}$ thin film, $\mathrm{c}$ Ln $\mathrm{R}$ versus $1 / \mathrm{K}_{B} \mathrm{~T}$ plot, $\mathbf{d} \mathrm{E}_{a}$ as a function of scandium doping

\begin{tabular}{|c|c|c|c|c|c|}
\hline Sample & Element & $\begin{array}{l}\text { Peak position } \\
\text { (B.E. in eV) }\end{array}$ & Oxidation state & FWHM & $\begin{array}{l}\text { Area ratio }\left(\mathrm{V} 2 \mathrm{p}_{3 / 2}\right) \\
\mathrm{V}^{+5}: \mathrm{V}^{+4}: \mathrm{V}^{+3}\end{array}$ \\
\hline \multirow[t]{9}{*}{ RTV } & \multirow[t]{3}{*}{$\mathrm{V} 2 \mathrm{p}_{3 / 2}$} & 516.35 & $\mathrm{~V}^{+3}$ & \multirow[t]{3}{*}{0.92} & \multirow[t]{9}{*}{$0.82: 1.0: 0.065$} \\
\hline & & 517.60 & $\mathrm{~V}^{+4}$ & & \\
\hline & & 518.72 & $\mathrm{~V}^{+5}$ & & \\
\hline & \multirow[t]{3}{*}{$\mathrm{V} 2 \mathrm{p}_{1 / 2}$} & 524 & $\mathrm{~V}^{+3}$ & \multirow[t]{3}{*}{2.4} & \\
\hline & & 525.10 & $\mathrm{~V}^{+4}$ & & \\
\hline & & 525.65 & $\mathrm{~V}^{+5}$ & & \\
\hline & \multirow[t]{3}{*}{ O1s } & 530.413 & & \multirow[t]{3}{*}{1.2} & \\
\hline & & 531.544 & & & \\
\hline & & 532.889 & & & \\
\hline \multirow[t]{10}{*}{ RTVS2.0 } & \multirow[t]{3}{*}{$\mathrm{V} 2 \mathrm{p}_{3 / 2}$} & 516.35 & $\mathrm{~V}^{+3}$ & \multirow[t]{3}{*}{1.2} & \multirow[t]{10}{*}{$0.097: 1.0: 0.231$} \\
\hline & & 517.60 & $\mathrm{~V}^{+4}$ & & \\
\hline & & 518.72 & $\mathrm{~V}^{+5}$ & & \\
\hline & \multirow[t]{3}{*}{$\mathrm{V} 2 \mathrm{p}_{1 / 2}$} & 524 & $\mathrm{~V}^{+3}$ & \multirow[t]{3}{*}{3.0} & \\
\hline & & 525.10 & $\mathrm{~V}^{+4}$ & & \\
\hline & & 525.65 & $\mathrm{~V}^{+5}$ & & \\
\hline & \multirow[t]{4}{*}{ O1s } & 530.03 & & \multirow[t]{4}{*}{1.4} & \\
\hline & & 530.41 & & & \\
\hline & & 531.66 & & & \\
\hline & & 533.07 & & & \\
\hline
\end{tabular}

(a)

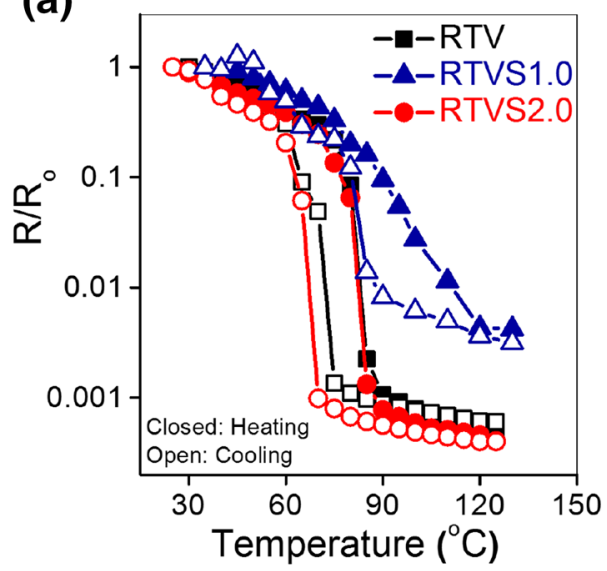

(c)

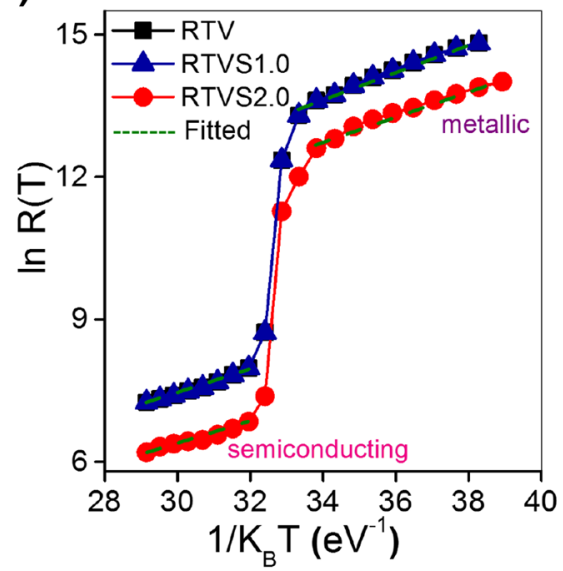

(b)

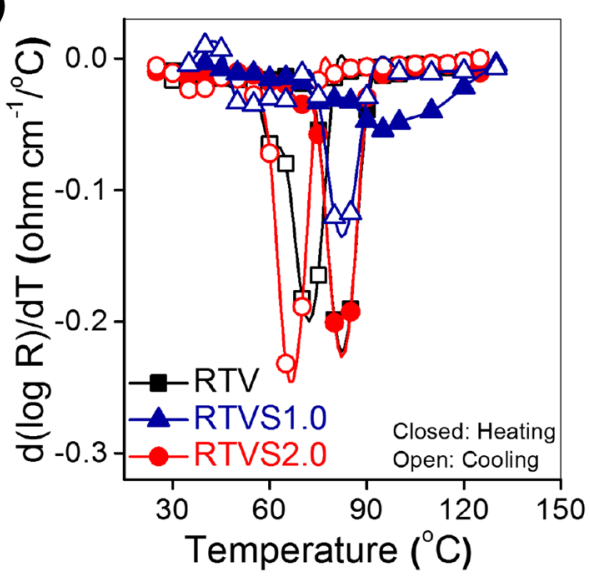

(d)

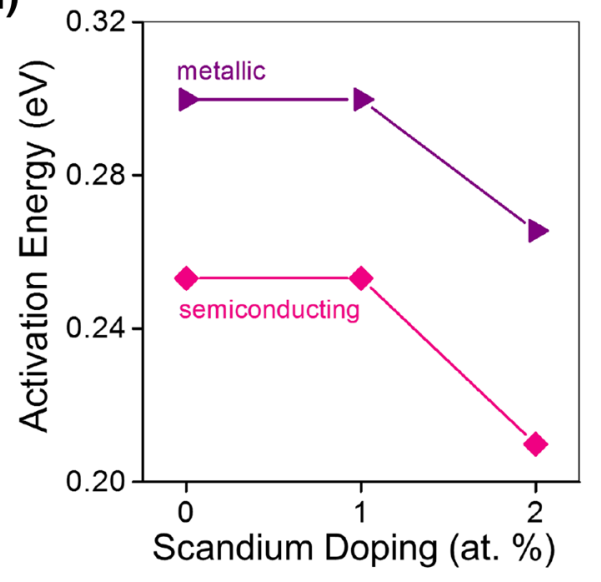


Similar trend was observed in the metallic phase though an increased value of activation energy was observed when compared with the semiconducting phase.

\subsubsection{Optical measurements:UV-visible and FTIR}

Figure 11 shows that the band gap value increases for scandium doped $\mathrm{VO}_{2}$ thin films which shows a blue shift in the absorption edge as observed for powder samples and the results are in good agreement with the theoretical reasoning.

$\mathrm{VO}_{2}$ upon transition from semiconducting phase to metallic phase shows a change in IR reflectance i.e. shows high reflectance in metallic phase and low reflectance in semiconducting phase as stated earlier [6]. To study the influence of scandium doping on the reflectance, temperature-dependent FTIR measurements were done on the

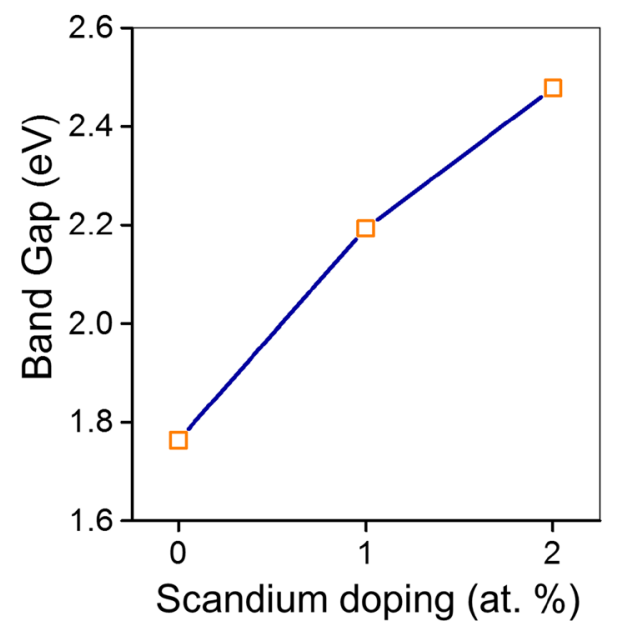

Fig. 11 Band gap as a function of scandium doping for $\mathrm{VO}_{2}$ thin films
RTV and RTVS2.0 (Figure S3, supplementary information) thin films in reflectance mode. The measurement was carried out after an interval of $5^{\circ} \mathrm{C}$ with an equilibrating time of 5 minutes before each measurement was carried out.

For undoped $\mathrm{VO}_{2}(\mathrm{RTV}), 80 \%$ change in the reflectance was observed at $\lambda=9.31 \mu \mathrm{m}$ and for 2.0 at. \% Sc-doped $\mathrm{VO}_{2}$ (RTVS2.0), $60 \%$ change in the reflectance was observed at $\lambda=8.48 \mu \mathrm{m}$ as seen in Fig. 12a. Figure $12 \mathrm{~b}$ shows the derivative plot as a function of temperature thus showing the tunability in the spectral range upon doping and hence making it suitable for a metamaterial type of application. In metallic phase, change in surface plasmon is only observed at $\lambda>2.0 \mu \mathrm{m}$ [40]. The dip in the reflectance observed in the range of $\lambda=2.5-4 \mu \mathrm{m}$ is basically due to the interference of atmospheric $\mathrm{CO}_{2}$ [46]. Dip around $\lambda=$ $10 \mu \mathrm{m}$ is attributed to the substrate (quartz).

\section{Conclusions}

In this study, we gave experimental evidence for the theoretical prediction on the influence of Sc-doping in modulating the optical spectrum of $\mathrm{VO}_{2}$. We synthesised Scdoped $\mathrm{VO}_{2}$ (M1) bulk and thin films by SCS and UNSPACM respectively, in two steps. XPS and Raman measurements confirmed the structural influence of Sc doping into $\mathrm{VO}_{2}$ thin films. Lowering of $611 \mathrm{~cm}^{-1}$ peak position to $606 \mathrm{~cm}^{-1}$ in Raman spectra was attributed to tensile strain resulting from Sc doping. A blue shift in the optical spectrum from $1.7 \mathrm{eV}$ (undoped) to $2.02 \mathrm{eV}$ (2.0 at. \%) was observed for both bulk as well as thin films which is in agreement with the theoretical report. Sc-doped $\mathrm{VO}_{2}$ showed four orders of magnitude change in resistance and an increased transition width maintaining the $\mathrm{T}_{S M T}$ of semiconductor to metal transition. $60 \%$ change in the IR reflectance was observed at $\lambda=8.48 \mu \mathrm{m}$ with 2.0 at. $\%$ of Sc-doping. Sc-doping only
Fig. 12 a Change in reflectance as a function of temperature, b derivative of reflectance as a function of temperature for RTV and RTVS2.0 thin films (a)

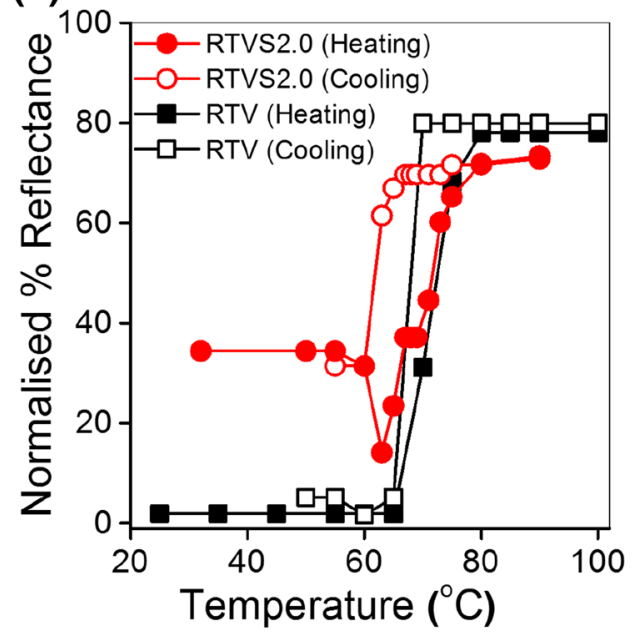

(b)

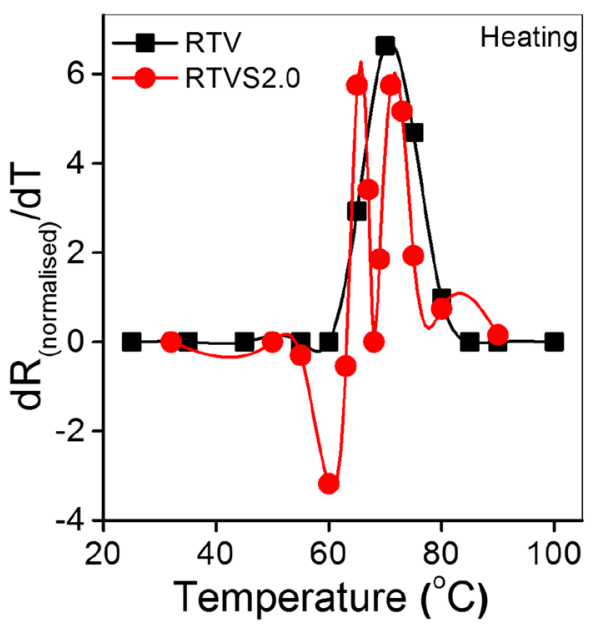

SN Applied Sciences A SPRINGER NATURE journal 
altered the optical spectrum of $\mathrm{VO}_{2}$ contrary to the theoretical prediction where changes in both $\mathrm{T}_{S M T}$ and band gap were reported. Tuning of both optical spectrum and $\mathrm{T}_{S M T}$ of $\mathrm{VO}_{2}$ may be possible by co-doping with other dopants for smart window applications.

\section{Supplementary information}

See Supplementary information for: SEM image of the undoped as well as Sc-doped $\mathrm{V}_{2} \mathrm{O}_{5}$ powder samples. Raman modes for $\mathrm{V}_{2} \mathrm{O}_{5}$ and $\mathrm{VO}_{2}$ as compared with the literature values; Temperature dependent reflectance plots for undoped (RTV) and 2.0 at. \% Sc-doped (RTVS2.0) $\mathrm{VO}_{2}$ thin films and V2p and O1s spectra for RTV and RTVS2.0 thin films that have been deconvoluted using Fityk software.

Acknowledgements DB thanks CSIR for providing Ph.D. fellowship. Centre for Nanoscience and Engineering (CeNSE) at IISc is acknowledged for providing access to Raman and I-V measurements. The authors thank Prof. S. Anantha Ramakrishna, Department of Physics, IIT Kanpur for providing access to high Temperature FTIR facility. Authors also like to thank Ms. Debadarshini Samantaray and Dr. Prem Wicram Jaschin for helping us to carry out SEM for the thin film and TEM imaging, respectively. The authors would also like to thank DSTFIST for providing funda for XRD facility.

\section{Compliance with ethical standards}

Conflict of interest The authors declare that they have no conflict of interest.

\section{References}

1. Kang L, Gao Y, Zhang Z, Du J, Cao C, Chen Z, Luo H (2010) Effects of annealing parameters on optical properties of thermochromic $\mathrm{VO}_{2}$ films prepared in aqueous solution. J Phys Chem C 114:1901-1911

2. Rajendra Kumar RT, Karunagaran B, Mangalaraj D, Narayandass SK, Manoravi P, Joseph M, Vishnu G (2003) Pulsed laser deposited vanadium oxide thin films for uncooled infrared detectors. Sensor Actuat A Phys 107:62-67

3. Fu WB, Ma H, Wei $Y$ et al (2017) Preparation and infrared response properties of vanadium dioxide nanowire/carbon nanotube composite film. J Mater Sci 52:7224-7231

4. Wen Q-Y, Zhang H-W, Yang Q-H, Chen Z, Long Y, Jing Y-L, Lin $Y$, Zhang P-X (2012) A tunable hybrid metamaterial absorber based on vanadium oxide films. J Phys D Appl Phys 45:235106

5. Kumar S, Maury F, Bahlawane N (2016) Electrical switching in semiconductor-metal self-assembled $\mathrm{VO}_{2}$ disordered metamaterial coatings. Sci Rep 6:37699

6. Zhang Z, Gao Y, Chen Z, Du J, Cao C, Kang L, Luo H (2010) Thermochromic $\mathrm{VO}_{2}$ thin films: solution-based processing, improved optical properties, and lowered phase transformation temperature. Langmuir 26:10738-10744

7. Lu Z, Li C, Yin Y (2011) Synthesis and thermochromic properties of vanadium dioxide colloidal particles. J Mater Chem 21:14776-14782
8. Lee CE, Atkins RA, Gibler WN, Taylor HF (1989) Fiber optic application for thermal switching in vanadium dioxide films. Appl Opt 28:4511-4512

9. Xia X, Chao D, Ng CF, Lin J, Fan Z, Zhang H, Shen ZX, Fan HJ (2015) $\mathrm{VO}_{2}$ nanoflake arrays for supercapacitor and Li-ion battery electrodes: performance enhancement by hydrogen molybdenum bronze as an efficient shell material. Mater Horiz 2:237-244

10. Chen L, Ruan Y, Zhang G, Wei Q, Jiang Y, Xiong T, He P, Yang W, Yan M, An Q, Mai L (2019) Ultrastable and high-performance Zn/ $\mathrm{VO}_{2}$ battery based on a reversible single-phase reaction. Chem Mater 31:699-706

11. Hassein-Bey ALS, Tahi H, Lafane S, Djafer AZA, Hassein-Bey A, Belgroune N (2016) Substrate effect on electrical properties of vanadium oxide thin film for memristive device applications. In: 2016 IEEE international conference on semiconductor electronics (ICSE), pp 240-243

12. Wu X, Wu Z, Ji C, Zhang H, Su Y, Huang Z, Gou J, Wei $X$, Wang J, Jiang $Y$ (2016) THz transmittance and electrical properties tuning across IMT in vanadium dioxide films by Al doping. ACS Appl Mater Interfaces 8:11842-11850

13. Wu C, Feng F, Xie Y (2013) Design of vanadium oxide structures with controllable electrical properties for energy applications. Chem Soc Rev 42:5157-5183

14. Son J-H, Wei J, Cobden D, Cao G, Xia Y (2010) Hydrothermal synthesis of monoclinic $\mathrm{VO}_{2}$ micro- and nanocrystals in one step and their use in fabricating inverse opals. Chem Mater 22:3043-3050

15. Liu M, Hwang HY, Tao H, Strikwerda AC, Fan K, Keiser GR, Sternbach AJ, West KG, Kittiwatanaku S, Jiwei L, Wolf SA, Omenetto FG, Zhang X, Nelson KA, Averitt RD (2012) Terahertz-fieldinduced insulator-to-metal transition in vanadium dioxide metamaterial. Nature 487:345

16. Powell MJ, Quesada-Cabrera R, Taylor A, Teixeira D, Papakonstantinou I, Palgrave RG, Sankar G, Parkin IP (2016) Intelligent multifunctional $\mathrm{VO}_{2} / \mathrm{SiO}_{2} / \mathrm{TiO}_{2}$ coatings for self-cleaning, energysaving window panels. Chem Mater 28:1369-1376

17. Xu S, Ma H, Dai S et al (2004) Study on optical and electrical switching properties and phase transition mechanism of $\mathrm{Mo}^{6+}$ -doped vanadium dioxide thin films. J Mater Sci 39:489-493

18. Bian J, Miao L, Zhao S et al (2015) Vanadium oxide films deposited on sapphire substrate with in situ AIN stress layer: structural, electric, and optical properties. J Mater Sci 50:5709-5714

19. Bhardwaj D, Singh DK, Krupanidhi SB et al (2020) Fabrication of smooth thin film of vanadium oxides $\left(\mathrm{VO}_{x}\right)$ using pulsed laser deposition. Appl Phys A 126:157

20. Bhardwaj D, Goswami A, Umarji AM (2018) Synthesis of phase pure vanadium dioxide $\left(\mathrm{VO}_{2}\right)$ thin film by reactive pulsed laser deposition. J Appl Phys 124:135301

21. Maruyama T, lkuta Y (1993) Vanadium dioxide thin films prepared by chemical vapour deposition from vanadium(III) acetylacetonate. J Mater Sci 28:5073-5078

22. Gopalakrishnan G, Ramanathan S (2011) Compositional and metal-insulator transition characteristics of sputtered vanadium oxide thin films on yttria-stabilized zirconia. J Mater Sci 46:5768-5774

23. Guinneton F, Sauques L, Valmalette JC, Cros F, Gavarri JR (2001) Comparative study between nanocrystalline powder and thin film of vanadium dioxide $\mathrm{VO}_{2}$ : electrical and infrared properties. J Phys Chem Solids 62:1229-1238

24. Rajeswaran B, Umarji AM (2016) Effect of $W$ addition on the electrical switching of $\mathrm{VO}_{2}$ thin films. AIP Adv 6:035215

25. Manning TD, Parkin IP, Pemble ME, Sheel D, Vernardou D (2004) Intelligent window coatings: atmospheric pressure chemical vapor deposition of tungsten-doped vanadium dioxide. Chem Mater 16:744-749 
26. Chen B, Yang D, Charpentier PA, Zeman M (2009) $\mathrm{Al}^{3+}$-doped vanadium dioxide thin films deposited by PLD. Sol Energy Mater Solar Cells 93:1550-1554

27. Zhou J, Gao Y, Liu X, Chen Z, Dai L, Cao C, Luo H, Kanahira M, Sun C, Yan L (2013) Mg-doped $\mathrm{VO}_{2}$ nanoparticles: hydrothermal synthesis, enhanced visible transmittance and decreased metal-insulator transition temperature. Phys Chem Chem Phys 15:7505-7511

28. Wang N, Liu S, Zeng XT, Magdassi S, Long Y (2015) Mg/Wcodoped vanadium dioxide thin films with enhanced visible transmittance and low phase transition temperature. J Mater Chem C 3:6771-6777

29. Netsianda M, Ngoepe PE, Catlow C, Richard A, Woodley SM (2008) The displacive phase transition of vanadium dioxide and the effect of doping with tungsten. Chem Mater 20:1764-1772

30. Lv X, Cao Y, Yan L, Li Y, Zhang Y, Song L (2018) Atomic layer deposition of $\mathrm{V}_{1-x} \mathrm{Mo}_{x} \mathrm{O}_{2}$ Thin films, largely enhanced luminous transmittance, solar modulation. ACS Appl Mater Interfaces 10:6601-6607

31. Yuan X, Zhang Y, Abtew TA, Zhang P, Zhang W (2012) $\mathrm{VO}_{2}$ : orbital competition, magnetism, and phase stability. Phys Rev B 86:235103

32. Gu D, Li Y, Zhou X, Xu Y (2019) Facile fabrication of composite vanadium oxide thin films with enhanced thermochromic properties. ACS Appl Mater Interfaces 11:37617-37625

33. Mlyuka NR, Niklasson GA, Granqvist CG (2009) Mg doping of thermochromic $\mathrm{VO}_{2}$ films enhances the optical transmittance and decreases the metal-insulator transition temperature. Appl Phys Lett 95:171909

34. Dai L, Chen S, Liu J, Gao Y, Zhou J, Chen Z, Cao C, Luo H, Kanehira $\mathrm{M}$ (2013) F-doped $\mathrm{VO}_{2}$ nanoparticles for thermochromic energysaving foils with modified color and enhanced solar-heat shielding ability. Phys Chem Chem Phys 15:11723-11729

35. Sun C, Yan L, Yue B, Liu H, Gao Y (2014) The modulation of metalinsulator transition temperature of vanadium dioxide: a density functional theory study. J Mater Chem C 2:9283-9293

36. Patil KC, Hegde MS, Rattan T, Aruna ST (2008) Chemistry of nanocrystalline oxide materials: combustion synthesis, properties and applications. World Scientific, Singapore
37. Rajeswaran B, Umarji AM (2017) Phase evolution and infrared transmittance in monophasic $\mathrm{VO}_{2}$ synthesized by a rapid nonequilibrium process. Mater Chem Phys 190:219-229

38. Bharathi R, Umarji AM (2013) Effect of Mo doping on the electrical properties of $\mathrm{VO}_{2}$ phase. In: International conference on advanced nanomaterials emerging engineering technologies, pp 424-425

39. Kamble VB, Umarji AM (2013) Gas sensing response analysis of p-type porous chromium oxide thin films. J Mater Chem C 1:8167-8176

40. Bharathi R, Naorem R, Umarji AM (2015) Metal-insulator transition characteristics of vanadium dioxide thin films synthesized by ultrasonic nebulized spray pyrolysis of an aqueous combustion mixture. J Phys D Appl Phys 48:305103

41. Sherikar BN, Umarji AM (2013) Synthesis of diopside by solution combustion process using glycine fuel. Int J Mod Phys Conf Ser 22:217-223

42. Sherikar BN, Umarji AM (2011) Effect of adiabatic flame temperature on nano alumina powders during solution combustion process. Trans Indian Ceram Soc 70:167-172

43. Wu JM, Liou LB (2011) Room temperature photo-induced phase transitions of $\mathrm{VO}_{2}$ nanodevices. J Mater Chem 21:5499-5504

44. Lee S, Ivanov IN, Keum JK, Lee HN (2016) Epitaxial stabilization and phase instability of $\mathrm{VO}_{2}$ polymorphs. Sci Rep 6:19621

45. Moulder JF, Stickle WF, Sobol PE, Bomben KD (1992) Handbook of X-ray photoelectron spectroscopy, edited by J Chastain. Perkin-Elmer, Eden Prairie

46. Pradhan JK, Ramakrishna SA, Rajeswaran B, Umarji AM, Achanta VG, Agarwal AK, Ghosh A (2017) High contrast switchability of $\mathrm{VO}_{2}$ based metamaterial absorbers with ITO ground plane. Opt Express 25:9116-9121

Publisher's Note Springer Nature remains neutral with regard to jurisdictional claims in published maps and institutional affiliations. 